\title{
OPEN Cost effective dye sensitized solar cell based on novel Cu polypyrrole multiwall carbon nanotubes nanocomposites counter electrode
}

\begin{abstract}
Shaista Rafique ${ }^{1 凶}$, Imran Rashid ${ }^{2} \&$ Rehana Sharif $^{3}$
In order to replace Pt CE in dye sensitized solar cell (DSSC) with simple and low cost, copper polypyyrol functionalized multiwall carbon nanotubes (Cu-PPy-FWCNTS) nanocomposite CE was fabricated by two step electrodeposition method on the stainless-steel substrate. The surface morphology, electrical conductivity, electrochemical properties of CU-PPy-FWCNTS nanocomposite CE electrodes were observed by using verity of techniques such as scanning electron microscopy, a four-probe method and electrochemical workstation. The Fourier transform infrared (FTIR) spectroscopy confirms the presence of FMWCNTS into PPy-FMWCNTS nanocomposite and XRD analysis verified the Cu nanostructures had come into being. The cyclic voltammogram and Tafel polarization measurement demonstrated that solution processed Cu-PPy-FWCNTS nanocomposites CE had smaller charge transfer resistance $\mathrm{R}_{\mathrm{ct}}\left(4.31 \Omega \mathrm{cm}^{2}\right)$ and higher electrocatalytic performance for $\mathrm{I}_{3}{ }^{-} / l^{-}$redox solution. Finally, the photovoltaic efficiency of DSSC assembled with CU-PPy-FWCNTS nanocomposite CE and Platinized CE were compared. The results revealed that the photovoltaic efficiency of DSSC with Cu-PPy-FWCNTS nanocomposites CE reached (7.1\%), which is superior to Platinized CE (6.4\%). The higher photovoltaic efficiency of the Cu-PPy-FMWCNTS film is due to copper nanostructures that lead to higher cathodic current density $\left(2.35 \mathrm{~mA} / \mathrm{cm}^{2}\right)$. The simple fabrication method, excellent electrocatalytic and photovoltaic properties permit the Cu-PPy-FWCNTS nanocomposites credible alternative CE to save the cost of DSSC.
\end{abstract}

DSSCs have received considerable scientific interest owing to their merits on easy fabrication process, cost effectiveness and maximum photovoltaic efficiency of $12.3 \%$ than traditional silicon solar cell ${ }^{1-6}$. The standard DSSCs are made up of dye sensitized Titanium Dioxide $\left(\mathrm{TiO}_{2}\right)$ working electrode, $\mathrm{I}_{3}{ }^{-} / \mathrm{I}^{-}$redox electrolyte and a Counter Electrode ${ }^{7-9}$. The counter electrode is one of the crucial and indispensable component of DSSc that plays a vital role to transport the electron from outer circuit to redox electrolyte ${ }^{10,11}$. The standard DSSC comprised of platinum counter electrode because of their good electric conductivity and excellent electrocatalytic activity toward triiodide reduction, however, its high price, rarity on earth and usage of complex vacuum system are the major bottlenecks in the large-scale production of DSSCs ${ }^{12-14}$. Therefore, scientists are struggling to develop some cost-effective catalytic materials as an alternative to platinum counter electrode. Numerous verities of cost-effective materials such as various carbonous materials, conducting polymers, metal oxides and transition metal carbides have been reported to substitute the platinum counter electrode $\mathrm{CE}^{15-21}$.

Recently, carbonaceous materials such as carbon black, graphite carbon nanotubes, graphene, and composite of previous materials have been reported as alternative catalytic materials to Pt CEs for large scale production of DSSC $^{22-28}$. The composite film of platinum nanoparticles (PtNP)/PANI deposited on poly(ethylene naphthalate) film have been investigated as an alternative $\mathrm{CE}$ and exhibit noticeable electrocatalytic activity for the reduction of triiodide due to combined effect of both PANI and $\mathrm{PtNP}^{29}$. Some polymer-based materials have been intensively used as hole conductor electrolyte additive and plastic substrate in DSSCs. The main advantage of using polymeric materials is the building of flexible and low-cost solar cells, which are beneficial for transportation in complex environments as compared with the rigid cells $\mathrm{s}^{30-35}$.

Recently cobalt triphosphide $\mathrm{CoP}_{3}$ on carbon paper was successfully synthesized by using a two step method and serviced as CE in DSSC. The synergistic effect of carbon paper and cobalt triphosphide can exhibit greatly

\footnotetext{
${ }^{1}$ Department of Physics, Government College Women University, Faisalabad, Pakistan. ${ }^{2}$ Electrical Engineering Department, The University of Lahore, Islamabad, Pakistan. ${ }^{3}$ Department of Physics, University of Engineering and Technology Lahore, Lahore, Pakistan. ${ }^{\circledR}$ email: shaistarafique@ymail.com
} 
improved photovoltaic efficiency in $\mathrm{DSSC}^{36}$. Composite film of $\mathrm{PP} / \mathrm{srTiO} \mathrm{O}_{2}$ nano particles synthesized by oxidative polymerization technique showed increased surface area, good electrocatalytic performance towards triodide reduction and exhibit $2.52 \%$ electrical conversion efficiency ${ }^{37}$. A new strategy have been designed to developed a composite of cobalt phosphide and cobalt molybdenum phosphorus $\mathrm{CoP} / \mathrm{CoMoP}$ on carbon paper via a low temperature phosphating technique and hydrothermal method. The DSSC assembled with composite $\mathrm{CoP} / \mathrm{CoMoP}{ }_{2} \mathrm{CE}$ delivered a high photovoltaic efficiency of $8.69 \%{ }^{38}$. The nitrogen doped mesopours carbon and cobalt phosphide nanoparticles composite COP/NMC CE based DSSC exhibit an impressive power conversion efficiency of $8.53 \%{ }^{39}$.

In this research work we used two step electrochemical deposition method for fabrication of inexpensive and simple $\mathrm{Cu}-\mathrm{PPy}$-FMWCNTs nanocomposites. The PPy-FMWCNTS nanocomposite film is synthesis on stainless steel substrate by chrono amperometric method and then the cyclic voltammetry is used to modify the obtained film with $\mathrm{Cu}$ nanostructures. Both these deposition methods are economical and simple for commercialization of DSSCs. It is expected that Cu-PPy-FMWCNTS nanocomposite CEs exhibit higher electrocatalytic performance and large electrical conductivity due to integrated effect of three constituents and will deliver the improved photovoltaic efficiency.

\section{Experimental}

Preparation of PPy, PPy-FMWCNTS, Cu-PPy-FMWCNTS nanocomposite CE. Cu-PPy-FMWCNTS nanocomposites films were prepared on the stainless-steel substrate with a simple electrochemical method by functionalizing MWCNTs in a concentrated solution of $\mathrm{H}_{2} \mathrm{SO}_{4}: \mathrm{HNO}_{3}(3: 1)$ and refluxed at $90{ }^{\circ} \mathrm{C}$ for one hour according to the previously reported method ${ }^{40}$. Electrochemical synthesis of Cu-PPy-FMWCNTS nanocomposites were performed in a standard three-electrode cell (SS sheet as a working electrode, saturated calomel electrode (SCE) as reference electrode, graphite as counter electrode) using Princeton 263 A electrochemical workstation. The PPy-FMWCNTS nanocomposite film was deposited on stainless steel substrate in an aqueous solution of $10 \mathrm{mg}$ FMWCNTS, 0.2 M PPy, and $0.2 \mathrm{M} \mathrm{H}_{2} \mathrm{SO}_{4}$ at an applied potential of $1.0 \mathrm{~V}$. The $\mathrm{Cu}$ was introduced on PPy-FMWCNTS nanocomposites films to form Cu-PPy-FMWCNTS through cyclic voltammetry in an aqueous solution of $0.01 \mathrm{MCuSO}_{4}$ and $0.5 \mathrm{MH}_{2} \mathrm{SO}_{4}$ at an applied potential of $-1.0 \mathrm{~V}$.

Fabrication of DSSCs. The $\mathrm{TiO}_{2}$ photoanode was prepared according to the literature ${ }^{1,41}$. In brief a compact $\mathrm{TiO}_{2}$ blocking layer was cast on to the FTO substrate by treating it in $50 \mathrm{mM} \mathrm{TiCl}_{4}$ isopropanol solution for 30 mints at $70{ }^{\circ} \mathrm{C}$, then sintered at $450{ }^{\circ} \mathrm{C}$ for $30 \mathrm{~min}$. Subsequently the $\mathrm{TiO}_{2}$ paste was loaded on the compact layer by doctor blade method. After coating the obtained $\mathrm{TiO}_{2}$, working electrode was annealed at $450{ }^{\circ} \mathrm{C}$ for $30 \mathrm{~min}$. These prepared films were socked in $0.5 \mathrm{mM} \mathrm{N719}$ dye solution in acetonitrile/tert-butanol $(1: 1 \mathrm{v} / \mathrm{v})$ overnight. The dye socked $\mathrm{TiO}_{2}$ photoanode were removed from the dye solution, rinsed with water and dried. Finally, the DSSCs with an active area of $1 \mathrm{~cm}^{2}$ were assembled by clamping the dye adsorbed $\mathrm{TiO}_{2}$ photoanode and CE together and the middest were filled with the drop of liquid electrolyte consisting of anacetonitrile. The DSSCs were wrapped with hot-melt thermoplastic Surlyn. Thermally reduced Pt CE is also used for comparison of photovoltaic efficiency.

Characterization and measurements. Fourier transform infrared spectrum (FTIR) of PPy, PPy-FMCNTS and Cu-PPy-FMWCNTS nanocomposites CEs was recorded in the range of 500-4000 $\mathrm{cm}^{-1}$ using an Infrared Spectrometric Analyzer. The electrical conductivity of the samples was carried out by four probe method. The X-ray diffractogram of the prepared samples were studied by 2001 Bruker-AXS diffractometer using CuKa radiation. The scanning electron microscopy (SEM; JSM-6480LV) was used to characterize the surface morphologies of CEs. Cyclic voltammogram (CV) were recoded with three-electrode arrangements using Princeton 263A electrochemical workstation. Saturated calomel was used as a reference electrode, graphite was used as a counter electrode and PPy, PPy-FMWCNTS, Cu-PPy-FMWCNTS nanocomposite films were used as working electrode. The photovoltaic efficiency of DSSC was obtained with a solar simulator under $100 \mathrm{~mW} / \mathrm{cm}^{2}$.

\section{Results and discussion}

Figure 1 shows the Fourier transform infrared spectrum of FMWCNTS, PPy and PPy-FMWCNTS nanocomposite CEs.

The absorption bands situated at $1556 \mathrm{~cm}^{-1}, 1720 \mathrm{~cm}^{-1}, 1189 \mathrm{~cm}^{-1}$ and $2879 \mathrm{~cm}^{-1} \mathrm{can}$ be viewed in FMCNTS curve. These bands are attributed to stretching of carbon nanotube backbone, $\mathrm{C}=\mathrm{O}$ stretching of $\mathrm{COOH}$ group, $\mathrm{C}-\mathrm{O}-\mathrm{C}$ stretching and $-\mathrm{CH}_{2}-$ stretching mode respectively, indicating the development of carboxylic groups $(-\mathrm{COOH})$ on the MWCNTS. The characteristic absorption peaks of the pure PPy appeared at $1404 \mathrm{~cm}^{-1}$ and $1213 \mathrm{~cm}^{-1}$ are indexed to $\mathrm{C}-\mathrm{N}$ stretching mode of vibration in PPy ring ${ }^{42-47}$. C-N and $\mathrm{C}-\mathrm{C}$ asymmetric and symmetric ring vibration at $1629 \mathrm{~cm}^{-1}$ and $1550 \mathrm{~cm}^{-1}$ was also noticed. $\mathrm{N}-\mathrm{H}$ stretching vibration and $\mathrm{C}-\mathrm{H}$ in plan deformation appeared at $1061 \mathrm{~cm}^{-148-51}$.

In PPy-FMWCNTS nanocomposite curve $\mathrm{C}-\mathrm{H}, \mathrm{C}-\mathrm{C}$ and $\mathrm{N}-\mathrm{H}$ bonds become weaker and $\mathrm{C}-\mathrm{N}$ bond become stronger. It was observed that the inclusion of FMWCNTS into PPy resulted in an enhanced intensity of some peaks with a little shift. This fact might be attributed to presence of carboxylic group on the nanotube surface that gives the interaction on the different reaction sites of PPy that facilitated the fast electron transportation between PPy and FMWCNT. It was also observed that some peaks were disappeared in PPy-FMWCNTS nanocomposite curve; this was because acid treated MWCNTS were wrapped in PPy thin film ${ }^{47,49}$.

The electrical conductivity of pure PPy, PPy-FMWCNTS and Cu-PPy-FMWCNTS nanocomposites were measured by four probe technique and the obtained results are listed in Table 1. 


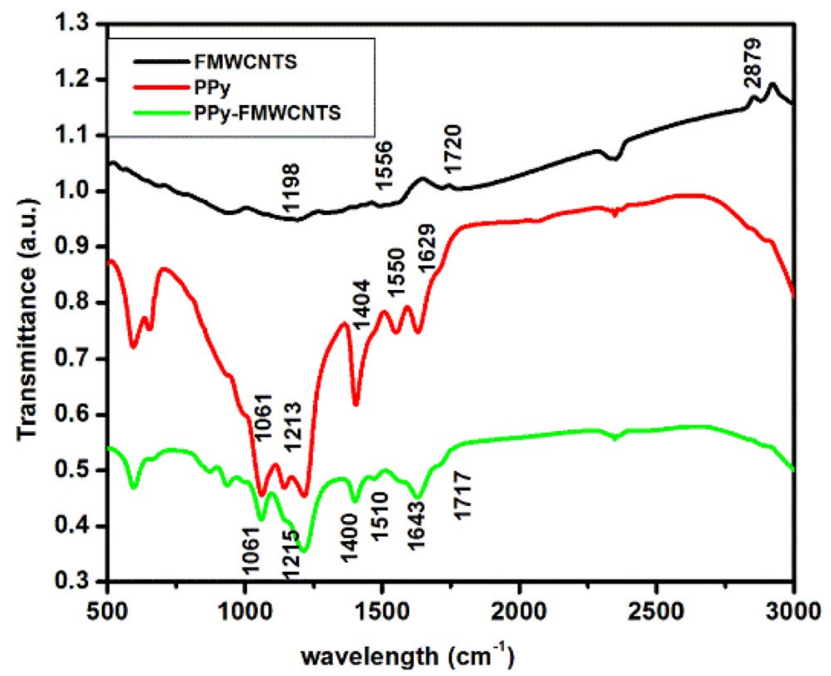

Figure 1. FTIR spectra of FMWCNTS, PPy and PPy-FMWCNTS.

\begin{tabular}{|l|l|}
\hline Electrodes & Conductivity (S/cm) \\
\hline PPy & 35 \\
\hline PPy-FMWCNTS & 250 \\
\hline Cu-PPy-FMWCNTS & 280 \\
\hline
\end{tabular}

Table 1. Conductivity measurements of PPy, PPy-FMWCNTS and Cu-PPy-FMWCNTS nanocomposites CEs.
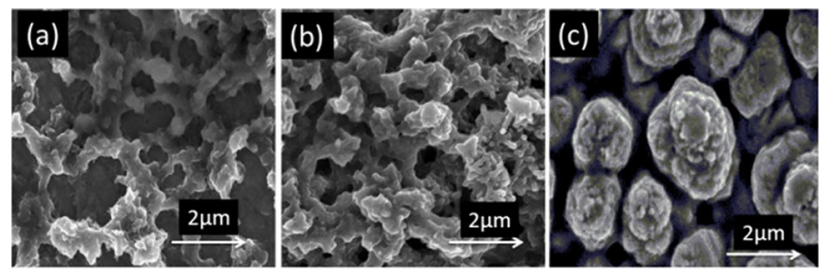

Figure 2. SEM images of (a) PPy, (b) PPy-FMWCNTS, (c) Cu-PPy-FMWCNTS.

The value of electrical conductivity is found to be $250 \mathrm{~s} / \mathrm{cm}$ for PPy-FMWCNTS for nanocomposite where, as the pure PPy has low conductivity of $35 \mathrm{~s} / \mathrm{cm}$. The lower value of conductivity of PPy is due to small localization length that is found to be $1.55 \mathrm{~nm}$. In case of FMWCNTS the localization length is around to $10 \mathrm{~nm}$ due to presence of large arrangement of $\pi$-conjugated structure hence it has high conductivity. Therefore, it is obvious that the introduction of highly conducting FMWCNTS into PPy matrix would increase the average localization length. Moreover, FMWCNTS are considered as a good electron acceptor and PPy is relatively good electron donor. So, there is strong interaction occurred between FMWCNTS and PPy quinoid rings which facilitated the fast movement of the charges between the two components and causes to increase the conductivity of PPyFMWCNTS nanocomposite film ${ }^{52,53}$. The deposition of $\mathrm{Cu}$ nanoparticles over PPy-FMWCNTS provides a unique path for facial electron transport through network assembly and causes an enhancement in electrical conductivity of $280 \mathrm{~s} / \mathrm{cm}$ for $\mathrm{Cu}$-PPy-FMWCNTS nanocomposite film ${ }^{54}$.

Figure 2a-c shows the SEM micrographs of pure PPy, PPy-FMWCNTS and Cu-PPy-FMWCNTS nanocomposites prepared by two step electrodeposition technique on stainless steel substrate. It can be clearly seen that PPy nanoparticles of average diameter of $100 \mathrm{~nm}$ are uniformly covered on SS sheet and exhibit a porous structure. It can be observed in Fig. $2 b$ that fiber like FMWCNTS are wrapped with PPy nanoparticles in PPyFMWCNTSnanocomposite film. This network assembly is helpful for electrical transport between PPy nanoparticle sand FMWCNTS ${ }^{42,55}$. It can also be observed in Fig. $2 \mathrm{c}$ that spherical like morphology of Cu nanostructures is homogenously covered on the surface of PPy-FMWCNTS.

These $\mathrm{Cu}$ nanostructures appeared as white bright flowers. Moreover, $\mathrm{Cu}-\mathrm{PPy}-\mathrm{FMWCNTS}$ nanocomposite film has porous structure and contributed large surface area to the sufficient adsorption of the electrolyte, which is helpful for the improvement of catalytic activity for $\mathrm{I}_{3}{ }^{-} / \mathrm{I}^{-}$redox solution ${ }^{54}$. 


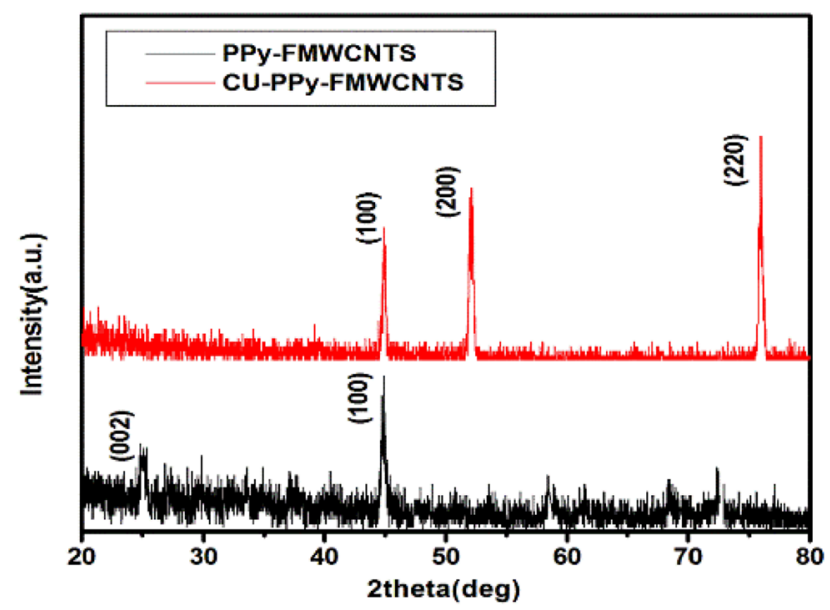

Figure 3. XRD spectra of PPy-FMWCNTs, Cu-PPy-FMWCNTs nanocomposites.

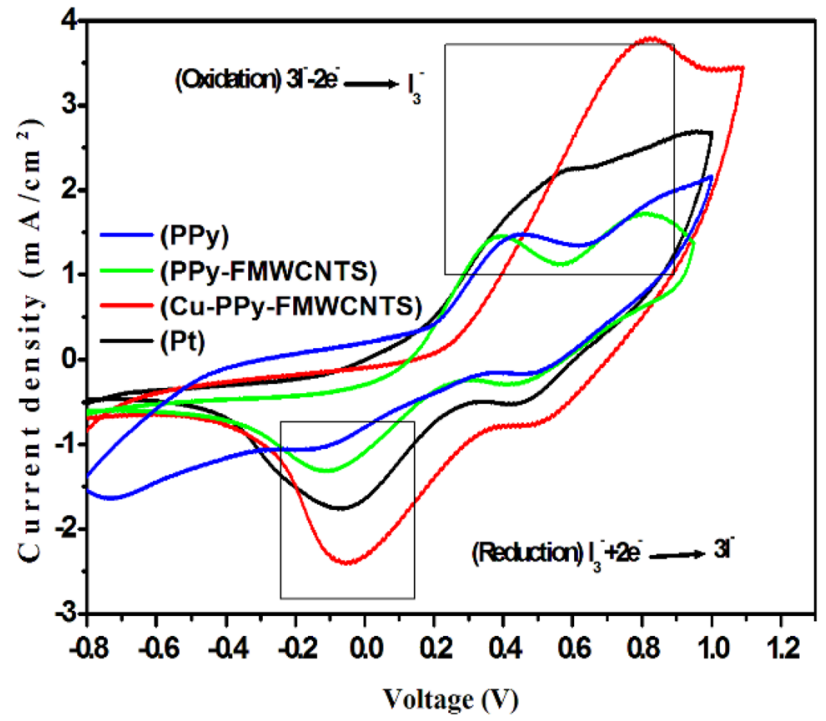

Figure 4. CVs of DSSC based on PPy, PPy-FMWCNTS, and Cu-PPy-FMWCNTS nanocomposites CEs.

X-ray diffraction pattern was carried out to analyze the crystalline structure of PPy-FMWCNTS and CuPPy-FMWCNTS nanocomposite as shown in Fig. 3. In case of PPy-FMWCNTS nanocomposites, two peaks at $2 \theta=25^{\circ}, 43^{\circ}$ indicating Bragg's reflections from (111) and (200) planes respectively ${ }^{49,56}$ which is mainly due to the presence of FMWCNTS. For Cu-PPy-FMWCNTS nanocomposites, the characteristic peaks at $2 \theta=25^{\circ}, 52^{\circ}$, $75^{\circ}$ having miller indices (111), (200), and (220) respectively. It is noticed the peak at $2 \theta=25^{\circ}, 43^{\circ}$ in Cu-PPyFMWCNTS nanocomposites film is disappeared. This fact is due to deposition of $\mathrm{Cu}$ nanostructures over the PPy-FMWCNTS film. These three diffraction peaks centered at $2 \theta=25^{\circ}, 52^{\circ}$, and $75^{\circ}$ represents the formation of metallic $\mathrm{Cu}$ nanostructures ${ }^{54,57}$. The presence of $\mathrm{Cu}$ nanostructures in $\mathrm{Cu}$-PPy-FMWCNTS nanocomposites film is confirmed by SEM results also.

Figure 4 shows the $\mathrm{I}_{3}^{-} / \mathrm{I}^{-}$system on the PPy, PPy-FMWCNTS, Cu-PPy-FMWCNTS nanocomposite CEs and Pt electrode in order to analyses the catalytic behavior of CEs. The electrolyte used in CV measurement is acetonitrile solution consisting of $10 \mathrm{mM}$ lithium iodide ( $\mathrm{LiI}), 0.1 \mathrm{M}$ lithium perchlorate $\left(\mathrm{LiClO}_{4}\right)$ as a supporting electrolyte and $1 \mathrm{mM} \mathrm{I}_{2}$ as $\mathrm{I}_{3}^{-} / \mathrm{I}^{-}$redox couple with the scan rate of $50 \mathrm{mV} / \mathrm{s}$. In the cyclic voltammograms, two sets of redox peaks were obtained, and the peaks obtained at the positive side are known as anodic peak and the left one is cathodic peak. The anodic peaks in the CV curves refer to the oxidation of iodide to tri-iodide and the cathodic peak is due to the reduction of tri-iodide ${ }^{58}$. All the CEs showed both oxidation and reduction peaks which show that the catalytic performance is comparable to thermally decomposed Ptelectrode. CE is responsible to the reduction of $\mathrm{I}_{3}{ }^{-} / \mathrm{I}^{-}$redox couple, therefore cathodic reaction is considered only. It is observed that the current density for Cu-PPy-FMWCNTS nanocomposite CE is higher than PPy, PPy-FMWCNTS nanocomposite which indicates rapid reaction rate of $\mathrm{I}_{3}{ }^{-} / \mathrm{I}^{-}$on $\mathrm{Cu}-\mathrm{PPy}-\mathrm{FMWCNTS}$ nanocomposite $\mathrm{CE}$ and lower charge transfer resistance $27,47,59$. The value of short circuit density $\mathrm{J}_{\mathrm{sc}}$ (shown in Table 2) follows the order of 


\begin{tabular}{|l|l|l|l|l|}
\hline CEs & $\mathbf{I}_{\mathbf{p c}}(\mathbf{m A ~ c m}$ & $-\mathbf{2})$ & $\mathbf{E}_{\mathbf{p c}}(\mathbf{V})$ & $\mathbf{J}_{\mathbf{0}}(\mathbf{m A ~ c m}$ \\
\hline PPy & 1.04 & -0.13 & 2.36 & $\mathbf{R}_{\mathbf{c t}}\left(\mathbf{\Omega} \mathbf{c m}^{2}\right)$ \\
\hline PPy-FMWCNTS & 1.29 & -0.11 & 2.42 & 5.43 \\
\hline Cu-PPy-FMWCNTS & 2.35 & -0.57 & 2.94 & 5.29 \\
\hline Pt & 1.73 & -0.06 & 2.63 & 4.31 \\
\hline
\end{tabular}

Table 2. Cyclic voltammetry and Tafel polymerization measurements of various counter electrodes.

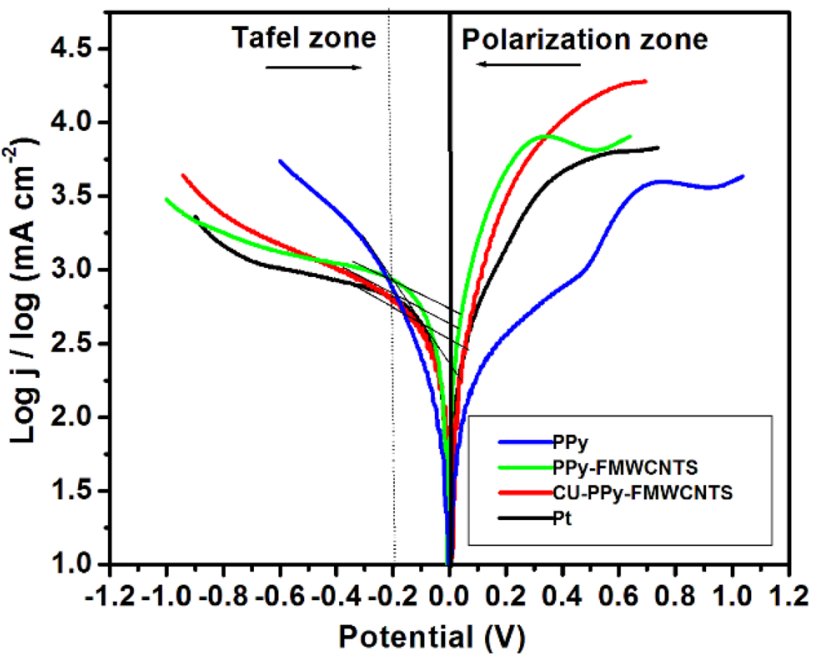

Figure 5. Tafel curves of DSSCs with, PPy, PPy-FMWCNTS and Cu-PPy-FMWCNTS nanocomposites as counter electrodes.

Cu-PPy-FMWCNTS $>$ Pt $>$ PPy-FMWCNTS $>$ PPy representing the same trend of electrocatalytic activity which could be explained by the reason that the active surface area increases in the same order.

It can be clearly seen from Fig. 4 that the reduction potential of Cu-PPy-FMWCNTS nanocomposite CE is more positive compared to Pt CE indicating the adsorption of liquid electrolyte on to the Cu-PPy-FMWCNTS nanocomposite surface ${ }^{42}$.

In order to confirm the electrocatalytic activity of the of $\mathrm{I}_{3}{ }^{-} / \mathrm{I}^{-}$redox couple on CEs, Tafel polarization curves were performed in a symmetrical cell containing the same electrolyte that was used in the assembly of DSSCs. In Tafel curve, the logarithm current density $(\log \mathrm{j})$ is a linear function of voltage (v) for the reduction of $\mathrm{I}_{3}{ }^{-} / \mathrm{I}^{-}$redox couple, as shown in Fig. 5. Theoretically, the curve at potential less than $0.4 \mathrm{v}$ and greater than $0.10 \mathrm{v}$ corresponds the Tafel zone ${ }^{41}$. In addition, exchange current density $\left(\mathrm{j}_{0}\right)$ is inversely proportional to charge transfer resistance $\left(\mathrm{R}_{\mathrm{ct}}\right)$ according to Eq. (1) and is measured by steep slope of the curve in the Tafel zone ${ }^{9}$.

$$
\mathrm{R}_{\mathrm{ct}}=\frac{\mathrm{RT}}{\mathrm{nFj}_{0}}
$$

In Eq. (1) $\mathrm{J}_{0}$ is the exchange current density, $\mathrm{R}$ is the gas constant, $\mathrm{T}$ is the absolute temperature, $\alpha$ is the distribution coefficient, $\mathrm{F}$ is Faraday's' constant, and $\mathrm{n}(\mathrm{n}=2)$ is the number of electrons involved in the reaction at the electrode and $\mathrm{R}_{\mathrm{ct}}$ is the charge transfer resistance at the electrode/electrolyte interface ${ }^{6,9}$.

The slopes of the curves for anodic and cathodic branches in Tafel zone are in the order of Pt $>\mathrm{Cu}-\mathrm{PPy}-$ FMWCNTS $>$ PPy-FMWCNTS $>$ PPy. A steep slope for anodic and cathodic branches in Tafel zone indicates the presence of higher electrical conductivity and large surface area. This is the key factor for higher electrocatalytic activity. The highest $\mathrm{j}_{\mathrm{o}}$ is observed for $\mathrm{Cu}$-PPy-FMWCNTS indicating its larger surface area and lower $\mathrm{R}_{\mathrm{ct}}$ resulting their higher catalytic activity for tri-iodide reduction and improved photovoltaic efficiency ${ }^{60}$.

Figure 6 compares the photocurrent voltage characteristic curve of DSSC based on various CEs and the obtained photovoltaic parameters are listed in Table 3.

The short circuit current density $\left(\mathrm{J}_{\mathrm{sc}}\right)$ value of Cu-PPy-FMWCNTS is highest as compared to PPy-FMWCNTS and PPy, This fact might be attributed to large electrical conductivity and homogenously distributed Cu nanostructures, which provides the larger surface areas for $\mathrm{I}_{3}^{-}$reduction as indicated in the CV curves ${ }^{4}$. Generally, $\mathrm{V}_{\mathrm{OC}}$ value of each photovoltaic device depend on the difference between the electronic fermi level in $\mathrm{TiO}_{2}$ semiconductor and the formal potential of $\mathrm{I}_{3}{ }^{-} / \mathrm{I}^{-}$redox couple on $\mathrm{CE}$. All the photovoltaic devices fabricated in the present work made up of same type of $\mathrm{TiO}_{2}$ photoelectrode and same composition of the liquid electrolyte, Therefore the $\mathrm{V}_{\mathrm{OC}}$ value of each photovoltaic device is mainly dependent on the electrocatalytic properties of the 


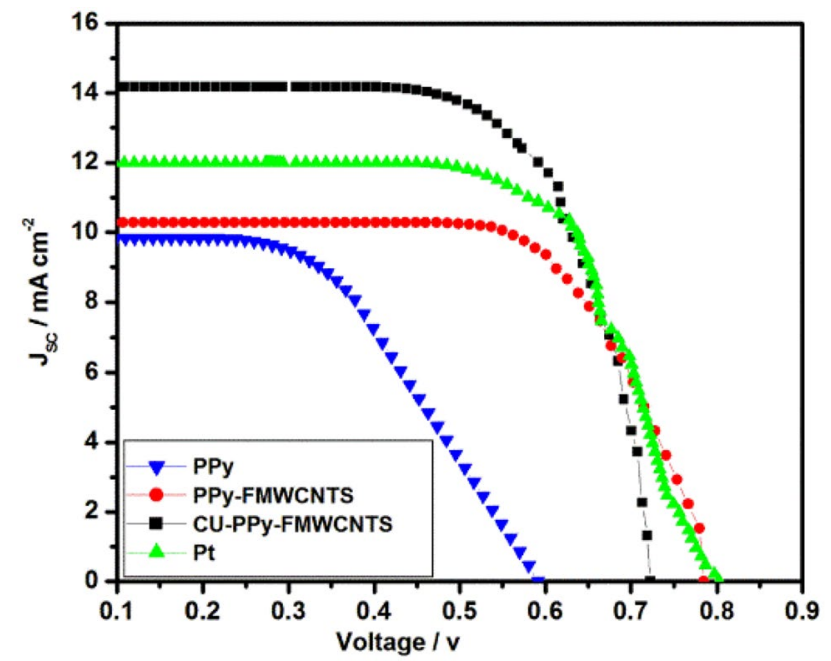

Figure 6. Photocurrent density-voltage curves of DSSCs with, PPy, PPy-FMWCNTS and Cu-PPy-FMWCNTS nanocomposites as CEs.

\begin{tabular}{|c|c|c|c|c|}
\hline CEs & $\mathrm{J}_{\mathrm{sc}}\left(\mathrm{mA} \mathrm{cm} \mathrm{cm}^{-2}\right)$ & $\mathrm{V}_{\mathrm{oc}}(\mathrm{V})$ & FF & $\eta(\%)$ \\
\hline PPy & 9.83 & 0.59 & 0.525 & $3.04 \pm .02$ \\
\hline PPy-FMWCNTS & 10.27 & 0.78 & 0.682 & $5.49 \pm .05$ \\
\hline Cu-PPy-FMWCNTS & 14.17 & 0.72 & 0.696 & $7.1 \pm .06$ \\
\hline $\mathrm{Pt}$ & 11.99 & 0.80 & .674 & $6.48 \pm .03$ \\
\hline
\end{tabular}

Table 3. Photovoltaic properties of DSSC with various nanocomposite CEs.

CEs. It is observed that $\mathrm{V}_{\mathrm{OC}}$ value of DSSC with Cu-PPy-FMWCNTS CE is highest among all the CEs study in the present work. This might be attributed to reduction potential on Cu-PPy-FMWCNTS CE is more positive than other CEs as shown in Fig. $4^{1,61,62}$. It is observed in Table 2 that $R_{c t}$ follows the order of PPy $>$ PPy-FMWCNTS $>$ Pt $>$ Cu-PPy-FMWCNTS. Moreover, The DSSC based on Cu-PPy-FMWCNTS CE shows the highest FF (0.696) value than PPy-FMWCNTS and PPy CEs but lower than Pt CE (0.674). This can possibly ascribe to its lower $\mathrm{R}_{\mathrm{ct}}\left(4.31 \Omega \mathrm{cm}^{2}\right)$ than PPy-FMWCNTS $\left(5.29 \Omega \mathrm{cm}^{2}\right)$, PPy $\left(5.43 \Omega \mathrm{cm}^{2}\right)$ and PtCE $\left(4.87 \Omega \mathrm{cm}^{2}\right)^{42}$.

It is obvious from whole results that excellent performance of $\mathrm{Cu}-\mathrm{PPy}$-FMWCNTS nanocomposite is due to uniformly distributed $\mathrm{Cu}$ nanostructures and large internal surface area which service the reduction and diffusion of triiodide $\left(\mathrm{I}_{3}^{-}\right)$throughout the nanocomposite film ${ }^{63}$. Therefore, it is concluded, that the novel CuPPy-FMWCNTS nanocomposite is a favorable alternative CE to replace the Pt CE.

\section{Conclusions}

In conclusion, flexible Cu-PPy-FMWCNTS nanocomposites films were fabricated by simple two step electrodeposition method on SS substrate and were used as an efficient catalyst CE for reduction of triiodide ions in DSSCs. A DSSC with Cu-PPy-FMWCNTS nanocomposites CE achieves a photovoltaic efficiency of 7.1\% which is comparable to the efficiency of solar cell based on traditional Pt CE. Higher photoelectric properties of CuPPy-FMWCNTS nanocomposites CE is due to its higher electrical conductivity $(280 \mathrm{~s} / \mathrm{cm})$, better electrocatalytic ability and lower charge transfer resistance $\left(4.31 \Omega / \mathrm{cm}^{2}\right)$, for $\mathrm{I}_{3}{ }^{-} / \mathrm{I}^{-}$redox reaction. The simple fabrication method and low cost of the Cu-PPy-FMWCNTS CE appears to be a potential substitute to the high-cost Pt for practical application of DSSCs.

Received: 12 May 2021; Accepted: 30 June 2021

Published online: 21 July 2021

\section{References}

1. Rafique, S., Sharif, R., Rashid, I. \& Ghani, S. Facile fabrication of novel silver-polypyrrole-multiwall carbon nanotubes nanocomposite for replacement of platinum in dye-sensitized solar cell. AIP Adv. 6(8), 085018-085021 (2016).

2. Ji, X., Liu, W., Leng, Y. \& Wang, A. Facile synthesis of ZnO@ TiO2 core-shell nanorod thin films for dye-sensitized solar cells. J. Nanomater. https://doi.org/10.1155/2015/647089 (2015).

3. Park, K.-H., Kim, S. J., Gomes, R. \& Bhaumik, A. High performance dye-sensitized solar cell by using porous polyaniline nanotubes as counter electrode. Chem. Eng. J. 260, 393-398 (2015).

4. Heo, S. Y., Koh, J. K., Kim, J. K., Lee, C. S. \& Kim, J. H. Three-dimensional conducting polymer films for pt-free counter electrodes in quasi-solid-state dye-sensitized solar cells. Electrochim. Acta 137, 34-40 (2014). 
5. Rajab, F. M. Effect of solvent, dye-loading time, and dye choice on the performance of dye-sensitized solar cells. J. Nanomater. 2016, 15 (2016).

6. He, B., Tang, Q., Wang, M., Ma, C. \& Yuan, S. Complexation of polyaniline and graphene for efficient counter electrodes in dyesensitized solar cells: Enhanced charge transfer ability. J. Power Sources 256, 8-13 (2014).

7. Li, Z. et al. Facile electropolymerized-PANI as counter electrode for low cost dye-sensitized solar cell. Electrochem. Commun. 11(9), 1768-1771 (2009).

8. Yue, G. et al. A highly efficient flexible dye-sensitized solar cell based on nickel sulfide/platinum/titanium counter electrode. Nanosc. Res. Lett. 10(1), 1-9 (2015).

9. Wu, M. et al. Economical Pt-free catalysts for counter electrodes of dye-sensitized solar cells. J. Am. Chem. Soc. 134(7), 3419-3428 (2012).

10. Bu, C., Tai, Q., Liu, Y., Guo, S. \& Zhao, X. A transparent and stable polypyrrole counter electrode for dye-sensitized solar cell. J. Power Sources 221, 78-83 (2013).

11. Keothongkham, K. et al. Electrochemically deposited polypyrrole for dye-sensitized solar cell counter electrodes. Int. J. Photoenergy https://doi.org/10.1155/2012/671326 (2012).

12. Fu, D., Huang, P. \& Bach, U. Platinum coated counter electrodes for dye-sensitized solar cells fabricated by pulsed electrodeposition-Correlation of nanostructure, catalytic activity and optical properties. Electrochim. Acta 77, 121-127 (2012).

13. Song, M. Y. et al. High efficient Pt counter electrode prepared by homogeneous deposition method for dye-sensitized solar cell. Appl. Energy 100, 132-137 (2012).

14. Lan, Z., Wu, J., Lin, J., Huang, M. \& Wang, X. Enhancing photovoltaic performance of dye-sensitized solar cells by using thermally decomposed mirror-like Pt-counter electrodes. Thin Solid Films 522, 425-429 (2012).

15. Hou, Y. et al. Rational screening low-cost counter electrodes for dye-sensitized solar cells. Nat. Commun. 4(1), 1-8 (2013).

16. Saito, Y., Kubo, W., Kitamura, T., Wada, Y. \& Yanagida, S. I-/I 3- redox reaction behavior on poly (3, 4-ethylenedioxythiophene) counter electrode in dye-sensitized solar cells. J. Photochem. Photobiol. A: Chem. 164(1), 153-157 (2004).

17. Fan, B., Mei, X., Sun, K. \& Ouyang, J. Conducting polymer/carbon nanotube composite as counter electrode of dye-sensitized solar cells. Appl. Phys. Lett. 93(14), 143103 (2008).

18. Murakami, T. N. \& Grätzel, M. Counter electrodes for DSC: Application of functional materials as catalysts. Inorgan. Chim. Acta 361(3), 572-580 (2008).

19. Wu, M., Lin, X., Hagfeldt, A. \& Ma, T. A novel catalyst of WO 2 nanorod for the counter electrode of dye-sensitized solar cells. Chem. Commun. 47(15), 4535-4537 (2011).

20. Wu, M., Lin, X., Hagfeldt, A. \& Ma, T. Low-cost molybdenum carbide and tungsten carbide counter electrodes for dye-sensitized solar cells. Angew. Chem. Int. Ed. 50(15), 3520-3524 (2011)

21. Jang, J. S., Ham, D. J., Ramasamy, E., Lee, J. \& Lee, J. S. Platinum-free tungsten carbides as an efficient counter electrode for dye sensitized solar cells. Chem. Commun. 46(45), 8600-8602 (2010).

22. Murakami, T. N. et al. Highly efficient dye-sensitized solar cells based on carbon black counter electrodes. J. Electrochem. Soc. 153(12), A2255-A2261 (2006).

23. Ramasamy, E., Lee, W. J., Lee, D. Y. \& Song, J. S. Nanocarboncounterelectrodefor dye sensitized solar cells. Appl. Phys. Lett. 90, 173103-173106 (2007).

24. Wang, H., Sun, K., Tao, F., Stacchiola, D. J. \& Hu, Y. H. 3D honeycomb-like structured graphene and its high efficiency as a counterelectrode catalyst for dye-sensitized solar cells. Angew. Chem. 125(35), 9380-9384 (2013).

25. Ju, M. J. et al. $\mathrm{N}$-doped graphene nanoplatelets as superior metal-free counter electrodes for organic dye-sensitized solar cells. ACS Nano 7(6), 5243-5250 (2013).

26 Fang, H., Yu, C., Ma, T. \& Qiu, J. Boron-doped graphene as a high-efficiency counter electrode for dye-sensitized solar cells. Chem. Commun. 50(25), 3328-3330 (2014).

27. Battumur, T. et al. Graphene/carbon nanotubes composites as a counter electrode for dye-sensitized solar cells. Curr. Appl. Phys. 12, e49-e53 (2012).

28. Miao, X. et al. Highly crystalline graphene/carbon black composite counter electrodes with controllable content: Synthesis, characterization and application in dye-sensitized solar cells. Electrochim. Acta 96, 155-163 (2013).

29. Peng, S. et al. Platinum/polyaniline transparent counter electrodes for quasi-solid dye-sensitized solar cells with electrospun PVDF-HFP/TiO 2 membrane electrolyte. Electrochim. Acta 105, 447-454 (2013).

30. Yin, X. et al. Facile synthesis of poly(3, 4-ethylenedioxythiophene) film via solid-state polymerization as high-performance Pt-free counter electrodes for plastic dye-sensitized solar cells. ACS Appl. Mater. Interfaces 5(17), 8423-8429 (2013).

31. Fan, L. et al. Efficiency improvement of flexible dye-sensitized solar cells by introducing mesoporous $\mathrm{TiO}_{2}$ microsphere. Sci. China Chem. 56(10), 1470-1477 (2013).

32. Dürr, M. et al. Low-temperature fabrication of dye-sensitized solar cells by transfer of composite porous layers. Nat. Mater. 4(8), 607-611 (2005).

33. Xia, J. et al. Influence of doped anions on poly(3,4-ethylenedioxythiophene) as hole conductors for iodine-free solid-state dyesensitized solar cells. J. Am. Chem. Soc. 130(4), 1258-1263 (2008).

34. Han, H., Bach, U., Cheng, Y.-B. \& Caruso, R. A. Increased nanopore filling: effect on monolithic all-solid-state dye-sensitized solar cells. Appl. Phys. Lett. 90(21), 213510 (2007).

35. Schmidt-Mende, L., Zakeeruddin, S. M. \& Grätzel, M. Efficiency improvement in solid-state-dye-sensitized photovoltaics with an amphiphilic ruthenium-dye. Appl. Phys. Lett. 86(1), 3504 (2005).

36. Gao, X. et al. In situ synthesis of cobalt triphosphate on carbon paper for efficient electrocatalyst in dye-sensitized solar cell. Sol. Energy 208, 289-295 (2020).

37. Ahmed, U. et al. An efficient platform based on strontium titanate nanocubes interleaved polypyrrole nanohybrid as counter electrode for dye-sensitized solar cell. J. Alloys Compd. 860, 158228 (2021).

38. Gao, X. et al. Sodium molybdate-assisted synthesis of a cobalt phosphide hybrid counter electrode for highly efficient dye-sensitized solar cells. ACS Appl Energy Mater. 4(4), 3851-3860 (2021).

39. Chen, M. et al. Molecular-level synthesis of cobalt phosphide nanocrystals confined in highly nitrogen-doped mesoporous carbon electrocatalyst for highly efficient dye-sensitized solar cells. ACS Sustain. Chem. Eng. 8(46), 17245-17261 (2020).

40. Alvaro, M., Aprile, C., Ferrer, B. \& Garcia, H. Functional molecules from single wall carbon nanotubes. Photoinduced solubility of short single wall carbon nanotube residues by covalent anchoring of 2, 4,6-triarylpyrylium units. J. Am. Chem. Soc. 129(17), 5647-5655 (2007).

41. Ghani, S. et al. Dye-sensitized solar cells with high-performance electrodeposited gold/polyaniline composite counter electrodes. Mater. Sci. Semicond. Process. 31, 588-592 (2015).

42. Xiao, Y. et al. Dye-sensitized solar cells with high-performance polyaniline/multi-wall carbon nanotube counter electrodes electropolymerized by a pulse potentiostatic technique. J. Power Sources 233, 320-325 (2013).

43. Bhandari, S., Deepa, M., Srivastava, A. K., Joshi, A. G. \& Kant, R. Poly(3,4-ethylenedioxythiophene)-multiwalled carbon nanotube composite films: Structure-directed amplified electrochromic response and improved redox activity. J. Phys. Chem. B 113(28), 9416-9428 (2009).

44. Sahoo, N. G., Jung, Y. C., So, H. H. \& Cho, J. W. Polypyrrole coated carbon nanotubes: synthesis, characterization, and enhanced electrical properties. Synthet. Met. 157(8), 374-379 (2007). 
45. Patole, A. \& Lubineau, G. Carbon nanotubes with silver nanoparticle decoration and conductive polymer coating for improving the electrical conductivity of polycarbonate composites. Carbon 81, 720-730 (2015).

46. Canobre, S. C., Xavier, F. F. S., Fagundes, W. S., de Freitas, A. C. \& Amaral, F. A. Performance of the chemical and electrochemical composites of PPy/CNT as electrodes in type I supercapacitors. J. Nanomater. 2015, 160 (2015).

47. Peng, S. et al. Facile fabrication of polypyrrole/functionalized multiwalled carbon nanotubes composite as counter electrodes in low-cost dye-sensitized solar cells. J. Photochem. Photobiol. A: Chem. 223(2), 97-102 (2011).

48. Imani, A., Farzi, G. \& Ltaief, A. Facile synthesis and characterization of polypyrrole-multiwalled carbon nanotubes by in situ oxidative polymerization. Int. Nano Lett. 3(1), 1-8 (2013).

49 Chakraborty, G., Gupta, K., Meikap, A. K., Babu, R. \& Blau, W. J. Synthesis, electrical and magnetotransport properties of polypyrrole-MWCNT nanocomposite. Solid State Commun. 152, 13-18 (2012).

50. Wu, T.-M., Chang, H.-L. \& Lin, Y.-W. Synthesis and characterization of conductive polypyrrole/multi-walled carbon nanotubes composites with improved solubility and conductivity. Compos. Sci. Technol. 69(5), 639-644 (2009).

51. Wu, T.-M., Chang, H.-L. \& Lin, Y.-W. Synthesis and characterization of conductive polypyrrole/multi-walled carbon nanotubes composites with improved solubility and conductivity. Compos. Sci. Technol. 1, 13-18 (2012).

52. Oh, E. J. et al. UV-Vis./NIR and transport studies of chemically synthesized soluble polypyrrole. Synthet. Met. 84(1), 147-148 (1997).

53. Joo, J. et al. Charge transport of the mesoscopic metallic state in partially crystalline polyanilines. Phys. Rev. B 57(16), 9567 (1998).

54. Ghani, S. et al. Polypyrrole thin films decorated with copper nanostructures as counter electrode for dye-sensitized solar cells. J. Power Sources 282, 416-420 (2015).

55. Wu, J. et al. High-performance polypyrrole nanoparticles counter electrode for dye-sensitized solar cells. J. Power Sources 181(1), $172-176$ (2008).

56. Yang, L. et al. Synthesis and characterization of polypyrrole nanotubes/multi-walled carbon nanotubes composites with superior electrochemical performance. J. Mater. Sci. Mater. Electron. 25(2), 1047-1052 (2014).

57. Ramesan, M. T. Synthesis, characterization, and properties of new conducting polyaniline/copper sulfide nanocomposites. Polym. Eng. Sci. 54(2), 438-445 (2014).

58. Roy-Mayhew, J. D., Bozym, D. J., Punckt, C. \& Aksay, I. A. Functionalized graphene as a catalytic counter electrode in dye-sensitized solar cells. ACS Nano 4(10), 6203-6211 (2010).

59. Wang, G., Xing, W. \& Zhuo, S. The production of polyaniline/graphene hybrids for use as a counter electrode in dye-sensitized solar cells. Electrochim. Acta 66, 151-157 (2012).

60 Wang, M. et al. CoS supersedes Pt as efficient electrocatalyst for triiodide reduction in dye-sensitized solar cells. J. Am. Chem. Soc. 131(44), 15976-15977 (2009).

61. Chen, J. et al. Polyaniline nanofiber/carbon film as flexible counter electrodes in platinum-free dye-sensitized solar cells. Electrochim. Acta 56(12), 4624-4630 (2011).

62. Luo, J. et al. Enhancement of the efficiency of dye-sensitized solar cell with multi-wall carbon nanotubes/polythiophene composite counter electrodes prepared by electrodeposition. Solid State Sci. 14(1), 145-149 (2012).

63. Wang, L., Zhang, K., Cheng, F. \& Chen, J. Polypyrrole-cobalt-carbon nanocomposites as efficient counter electrode materials for dye-sensitized solar cells. Sci. China Chem. 57(11), 1559-1563 (2014).

\section{Acknowledgements}

This research work was supported by the Higher Education Commission of Pakistan (PIN NO.112-270962PS1-556(50022392). The authors are gratefully thankful to the National Institute for Biotechnology and Genetic Engineering (NIBGE) and Pakistan Council of Renewable Energy Technologies (PCRET) for providing their facilities to carry out the research.

\section{Author contributions}

Dr. S.R. and E.I.R. fabricate the device. Dr. S.R. wrote the main manuscript text and analyzed the results. Dr. R.S. supervised the project. All authors reviewed the manuscript.

\section{Competing interests}

The authors declare no competing interests.

\section{Additional information}

Correspondence and requests for materials should be addressed to S.R.

Reprints and permissions information is available at www.nature.com/reprints.

Publisher's note Springer Nature remains neutral with regard to jurisdictional claims in published maps and institutional affiliations.

Open Access This article is licensed under a Creative Commons Attribution 4.0 International License, which permits use, sharing, adaptation, distribution and reproduction in any medium or format, as long as you give appropriate credit to the original author(s) and the source, provide a link to the Creative Commons licence, and indicate if changes were made. The images or other third party material in this article are included in the article's Creative Commons licence, unless indicated otherwise in a credit line to the material. If material is not included in the article's Creative Commons licence and your intended use is not permitted by statutory regulation or exceeds the permitted use, you will need to obtain permission directly from the copyright holder. To view a copy of this licence, visit http://creativecommons.org/licenses/by/4.0/.

(C) The Author(s) 2021 